\title{
Determining Thermal Specifications for Vegetated GREEN Roofs in Moderate Winter Climates
}

\author{
Christoph Maria Ravesloot ${ }^{1,2,3}$ \\ ${ }^{1}$ City Development Department, City of Rotterdam, Netherlands \\ ${ }^{2}$ School of Engineering TOI, Inholland University of Applied Science, Alkmaar, Netherlands \\ ${ }^{3}$ Research Center Sustainable Portcity RDM, Rotterdam University of Applied Science, Rotterdam, Netherlands \\ Correspondence: Christoph Maria Ravesloot, Rotterdam University of Applied Science, Rotterdam, NL-3089JA, \\ Netherlands. Tel: 3-161-691-0660. E-mail: christophmaria@ravesloot.nl
}

Received: August 26, 2013

doi:10.5539/mas.v9n13p208

\author{
Accepted: October 10, 2013 \\ Online Published: November 30, 2015 \\ URL: http://dx.doi.org/10.5539/mas.v9n13p208
}

\begin{abstract}
Because local weather conditions in moderate climates are changing constantly, heat transfer specifications of substrate and vegetation in vegetated green roofs also change accordingly. Nevertheless, it is assumed that vegetated green roofs can have a positive effect on the thermal performance of construction in winter conditions. Is there proof from scientific research and field testing for this assumption? To answer this question, research is conducted with the main research question: Which parameters defining thermal performance for vegetated green-roof construction for a moderate winter climate like that in the Netherlands can be determined from existing literature, and how do these parameters influence thermal performance? Literature research was executed on monitoring and testing of thermal specifications of vegetated green roofs. Models with physical parameters on vegetated green roofs were studied and compared. The first goal was to make a list of all physical parameters and corresponding variables valid in the Dutch moderate-winter climate. None of the models that were found in the literature seemed to cover all physical processes. These models use parameters and variables to calculate the overall u-value of substrate and vegetation. Nevertheless, one nearly complete model was used for a sensitivity test on variables. Maximum and minimum values of variables were calculated in the model to determine the influence on the outcome in terms of u-value. From this analysis, a distinction could be made between variables influencing the u-value strongly and other variables influencing the outcome weakly.

The modelling showed that three variables were influencing the model calculations moderately strongly and therefore the thermal performance of the vegetated green-roof substrate and vegetation. These variables are not consistent with parameters modeling or calculating u-value in constructions. This finding means that contribution to thermal insulation by extensive vegetated green-roof substrate and vegetation in terms of $\mathrm{u}$-value would be negligible. Only a small theoretical contribution to thermal insulation can be argued from weak variables. To be sure about this small theoretical contribution to the u-value of the roof construction, this u-value was used as input for energy-use calculations for residential buildings. These calculations show that such a small increase of the u-value leads to no visible reduction in energy use for heating in winter conditions. The contribution is negligible compared to the influence of the u-value from extra insulation under the roof.
\end{abstract}

For vegetated green roofs in such moderate winter climates as in the Netherlands, additional u-value will have to be proven specifically, because the modelling shows that, in general, no contribution to thermal insulation can be expected.

Keywords: vegetated green roofs, moderate climates, residential building, U-value, energy savings

\section{Introduction}

Green-roof construction companies advertise with specifications for their products. To establish these specifications, some method of testing or calculating is used, each company using a different one. There is no consistency in the methods. Scientists can validate theoretical calculation methods with field tests. Vice versa, field tests can be elaborated and extrapolated into theoretical models. To determine thermal specifications of vegetated green roofs, a lot of different methods are used, by green-roof construction companies, for example. Differences in construction and differences in use of materials and layers give reason for specific methods on 
several locations with changing weather conditions. Then there are differences in approach from the perspective of energy-use calculation. Does the model accommodate thermal benefits from the vegetated green roof in energy-use calculation for heating? Because of these options, there seems to be little common ground for comparing results from theoretical models or from field tests. This situation is a problem for the extension of vegetated green-roof markets in such moderate climates. Clients cannot compare offers for the vegetated greening of their roofs because specifications are not comparable. Public authorities have a hard time making governance programs if thermal specifications cannot be pinned down to one uniform theoretical model or method. If the specification of vegetated green roofs were based on a uniform method, more clients would buy vegetated green roofs, and more public authorities would be willing to support large-scale application with policies and governance models, including subsidies or tax incentives on the argument of extra insulation for the building.

During 2012 and 2013, research was executed to address the problem of uniform methods of determining thermal specifications of extensive green roofs in the Netherlands (Delemarre and Somers 2013; Huang 2013, Klaasman 2013). First, the research concentrated on scientific papers from journals and conferences. Focus was on thermal specifications describing the changes in u-value of the vegetated green-roof construction, related to the overall construction of the roof underneath. The approach chosen here was for heating-energy and not for cooling-energy use. The main research questions were: How are thermal specifications of extensive green roofs on residential buildings in heating conditions of the building being modeled in scientific research, how is thermal behavior tested in field tests or laboratory tests, and how can contribution to overall u-value improvement and energy saving be assessed? This paper describes the research and the consequences of the conclusions for innovation in vegetated green roofs on thermal aspects and for commissioning in private and public procurement or in supporting Dutch public governance and policies Teeuw Ravesloot 2009). The paper shows:

1) how winter conditions on extensive green roofs can be understood in terms of physical parameters;

2) how many variables are included in models constructed with the physical parameters;

3) how a sensitivity analysis on vegetated green-roof thermal parameters taken from existing literature shows significance for some vegetated green-roof variables defining thermal behavior;

4) how thermal parameters interrelate to potential extra u-value from substrate and vegetation;

5) why energy-use calculations for residential buildings with possible input form vegetated green-roof specifications will show no savings from vegetated green roofs in a moderate climate.

\section{Method}

The first research question is how to establish a model for describing specifications for the thermal behavior of extensive green roofs? The model needs to be usable in the private context of comparing bids and contracting. In the case of the construction of vegetated green roofs on new building or on existing roofs, the client must be able to compare bids. The comparison, based on a uniform model, needs to be accurate and reliable enough. The same uniform model also needs to be suitable for reference in public authorities' governance models and related policies. If public authorities support construction of vegetated green roofs based on the same uniform model and method, then market share is supposed to grow faster. This scenario would be beneficial for clients, contractors, and authorities as a whole.

The problem is that companies use their own specific method for examining and determining thermal specifications. Some of the methods refer to similar scientific background, some to similar practical guidelines. The four major companies in the Netherlands, delivering vegetated green-roof systems for both new and for existing roofs, refer to thermal specifications differently.

Table 1. Specimen and corresponding thermal coefficient

\begin{tabular}{llc}
\hline Company & Product type & Thermal coefficient $[\mathrm{W} / \mathrm{mK}]$ \\
\hline Specimen N & Standard and lightweight type & 0.17 \\
Specimen O & Optimized water-retention lightweight types & 0.17 \\
Specimen X & $\begin{array}{l}\text { Sedum-Moss-Herb lightweight types 25-100 } \\
\text { (depending on humidity) }\end{array}$ & $0.038-2.15$
\end{tabular}




\begin{tabular}{llc}
\hline Company & Product type & Thermal coefficient $[\mathrm{W} / \mathrm{mK}]$ \\
\hline Specimen Z & $\begin{array}{l}\text { Sedum-type lightweight } 75 \\
\text { (depending on humidity) }\end{array}$ & $0.035-0.2$ \\
\hline
\end{tabular}

Table 1 shows the comparison of thermal specifications of four major systems for extensive green roofs in the Netherlands. Although the units of the specifications are the same $[\mathrm{W} / \mathrm{mk}]$, the background research for establishing the thermal parameters is not specified or elaborated. Therefore, the specifications cannot be compared. (Specific branch names and product types are known by the author and can be provided if necessary).

There seems to be no general model and method for finding thermal specifications of vegetated green roofs. It is even questionable if such a model would be realistic and feasible. The conditions of roofs, seen from the thermal perspective are very different and dynamically changing, including differences in climate and building technology as well as dynamic influences from weather, the day- and night cycles, urban climate influences such as pollution, etc..

The goals of the research are to make an overview of scientific models and methods known from literature and to put these models and methods to the test. Are there parameters and variables in these models and methods that can be part of one uniform model and method for describing thermal specifications in a moderate climate like that of the Netherlands? The literature search was executed for all types of vegetated green roofs. The models and methods aimed at are supposed to be used specifically for extensive green roofs, since the potential for marked expansion is biggest there. Investments can be expected to be the lowest for extensive green roofs. The uniform model and method sought herein will be functional within the local climate and weather conditions of the roofing landscape in Dutch cities as well as in cities around the world with similar thermal conditions.

The second research question is how to find the parameters and variables that most influence thermal specifications. The focus of this paper is on extensive vegetated green roofs. From the parameters and variables for extensive vegetated roofs, we ask how big the influence in the overall $\mathrm{u}$-value of the roof construction would be and how this influence would show in energy-saving calculations for residential buildings?

Summarizing the method of research consists of literature reading, comparison of current Dutch extensive greenroofing systems, selection of relevant conditions for thermal parameters, selection of variables with sensitivity analyses, input of relevant variables and parameters in energy-heating-use calculation in housing and in cooling capacity, and cooling-energy-use calculation for an office building. Finally, there is a discussion on the verification of the method used and validation of the results.

\section{Research on Thermal Specifications}

For the past fifteen years, research has been performed and published (Barrio 1998, Jim and Tsang 2010, Lundholm et al. 2014) showing a full bandwidth of physical properties of vegetated green-roof systems. Papers show that there are many variables defining thermal conditions, and these variables are broad in their physical description. Analyzing this research shows that there are two main types of conditions researchers report on:

1 thermal conditions from the perspective of heating the rooms in the building underneath;

2 thermal conditions from the perspective of cooling the rooms in the building underneath.

The thermal conditions from climate and weather influence the thermal behavior of a vegetated green-roof system. The thermal specifications derive from that fact, as well as how dynamical the vegetated green roofs' behavior might be. Parameters classify a specific physical phenomenon describing a thermal influence of the vegetated green-roof system. Variables define the physical process within a parameter. This paper reports on the variables and parameters from the perspective of the heating of residential buildings. There are four angles of approach to investigating the thermal conditions, parameters, variables, and thus specifications for this winter situation:

1) Are the conditions used for input described as real-time field conditions from measuring on an actual extensive green roof (Sfakianaki et al. 2009)?

2) Are the conditions simulated in a laboratory setup?

3) Was the goal of the field and laboratory tests to measure the thermal specifications from practical constructions to research the thermal behavior of extensive green roofs?

4) Or, the other way around, are the thermal specifications used to elaborate a thermal model that is going to 
be used to calculate and estimate thermal specifications of current and future vegetated green-roof types?

In this paper, the thermal behavior affecting the city climate is not included (Banting et al. 2005; Alexandri and Jones 2008; Susca et al. 2011) since these conditions are not directly relevant for private clients of vegetated green roofs. Neither will psychological effects of vegetated green roofs and psychological approaches to energy saving with vegetated green roofs be included (Townshend 2007). This paper focusses on thermal behavior of extensive green roofs on the scale of a building due to conditions on the roof and in the building. Research on intensive green roofs is noted but not included (Tsang et al. 2011). Extensive green roofs in this paper are defined as the substrate and vegetation on flat or slightly tilted roofs including supporting layers, to a maximum of $120 \mathrm{~mm}$ in the height of the soil substrate. The vegetation on most green roofs consists of sedum, moss, and herbs. On extensive green roofs there should be no perennials nor grasses or shrubs. The layers include waterproofing, root barrier, protection- and separation fleece, drainage layer, separation membranes, filter membrane, erosion reinforcement web, soil substrate, and vegetation.

After reading and discussing the scientific papers about thermal specifications and conditions, an analysis is executed to find the relevant parameters defining thermal behavior of extensive green roofs. This analysis differentiates for winter conditions. Doing so makes it easier to distinguish those parameters influencing the uvalue of the total roof construction as opposed to those parameters not influencing the u-value. The thermal dynamics of vegetated green roofs are big. Amplitudes in variables can make the behavior change from winter to summer conditions within hours. Thus differentiation is necessary. Running a thermal model with the most significant parameters and variables in the lowest and highest amplitudes demonstrates the sensitivity of the model for these parameters and variables. The output from this sensitivity analysis answers the first research question.

\section{Models on U-Value and Thermal Specifications}

Thermal effects from vegetated green roofs on the energy use of buildings have been reported in several ways. Hilten reports positive and negative effects (Hilten 2005). Jim and Peng report positively on extensive tropical green roofs (Jim and Peng 2011). Morau et al. report positive effects from shading by vegetation on green roofs in a tropical climate (Morau et al. 2012). Part of the effect is caused by the shading from the vegetated green roof. Here is where two different effects on energy use by vegetated green roofs become visible. One effect is on the energy use for heating (Jaffal et al. 2012); the other is for cooling a building. Climate and weather conditions strongly influence thermal conditions in soil layers and vegetation (Deardoff 1987).

Several attempts to model thermal behavior have been published. Ouldboukhitine et al. describe a coupled heat and mass-transfer model (Ouldboukhitine et al. 2011). It has become clear from field testing that fairly good insulated roof constructions react with little amplitude on the changing thermal conditions of vegetated green roofs, compared to non-insulated roofs (Niachou 2000, Castleton et al. 2010). From field testing and from the theory of building physics, several attempts were made to compose a model for the thermal behavior of vegetated green roofs (Getter et al. 2011). In these models, different parameters and variables are used to show the physical processes in and around the vegetated green-roof construction. A simple model was used to show the effects of rooftop gardens on the energy consumption of a commercial building in a tropical humid climate (Wong et al. 2003). The model uses merely the u-value to calculate the differences in conditions. It is more or less a simplification of the vegetated green-roof system to one layer, expressed in one u-value for the complete system. A thermal model of three layers was described by Del Barrio. This model consists of the roof construction, the substrate with the soil, and a canopy layer with the vegetation (Del Barrio 1998). Frankenstein and Koenig extended a similar model by distinguishing only the two separate layers of substrate and vegetation (Frankenstein Koening 2004). Here, separate parameters are used to make modeling of smaller effects on the heat transfer possible: height of the vegetation, Leaf Area Index (LAI), the Albedo effect, and the density of the vegetation. Sailor used this model to integrate it into an energy use calculation (EnergyPlus). This combination of modeling and calculation was tested on a university building in Florida (USA) and then used to calculate energy effects on buildings in Chicago and Houston (USA) (Sailor 2008). Kumar and Kaushik developed a model to calculate the effects on energy use by extending the Del Barrio model. Here also the shading of plants, again the LAI (Leaf Area Index) and the temperature in the canopy, is modeled. The air temperature in the canopy decreases the amplitude, thus resulting in smaller heat transfer through the roof (Kumar Kaushik 2005).

From all models, it can be concluded that the more sophisticated they become, the less the accountability there might be. The clearer the relative influence of all partial variables within specific parameters shows, the less accurate the calculated values might be. In one model, even percentages were calculated (Feng et al. 2010). From all heat transferred outside and above the vegetated green roof, $58.4 \%$ was evaporated through the 
substrate and the vegetation, where $30.9 \%$ of the heat was lost through infrared radiation. These are the two largest parameters, compared to, for instance, $9.5 \%$ heat loss through photosynthesis of the vegetation.

Some of the many parameters mentioned in the literature, such as conductivity, heat capacity, short-wave reflection and Albedo, are dependent on the humidity of the substrate soil layer (Sailor et al. 2008). Some more optical parameters like shape and age of vegetation can vary, but are nonetheless supposed to be fixed parameters, since there seems little use in trying to model nature. Doing so might compromise the accountability as well.

\section{Selecting One Model}

The last generation of models shows many smaller variables influencing the total thermal behavior of vegetated green roofs. Some of the variables are dependent on weather and outside conditions like temperature, radiation from the sun, humidity, and rainfall. The physical conditions of the vegetation that cannot be influenced by the design or innovation of the vegetated green roof or one of its layers, react to those conditions. Other variables can be influenced by design, construction, and maintenance; like particles in the soil substrate and thickness of the layers, capacity of the drainage, and specifications of filters between layers. Modeling these variables in parameters in an equation that calculates the total heat transfer through the vegetated green-roof construction, gives insight without having to make an actual field or laboratory test. It also makes it possible to calculate many variations in conditions systematically. After that, it is possible to calculate the influence of differences in vegetated green-roof construction to the overall energy use of buildings. However, the models should be validated prior to use in practice.

The heat-transfer model of Ouldboukhitine et al. is a combination of the models from Sailor and Frankenstein, Koenig. This model seems to be the most complete and sophisticated in approach to parameters, two separate layers of soil substrate, and vegetation, as well as in approach to humidity and moisture in both layers.

In this model, parameters representing conditions in and on the vegetated green-roof system are interrelated. The model provides a possibility to vary the input variables in their full bandwidth. Doing so would provide an impression of how the influence of each parameter, according to the model, would be on the overall thermal behavior. This kind of sensitivity analysis is important in finding the most influential parameters and conditions that have to be present in a uniform method to describe thermal factors of vegetated green roofs for the Dutch moderate climate. On the other hand, such a sensitivity analysis also provides reason to exclude some minor influencing variables because the variation in input hopefully does not affect the overall thermal behavior. The fewer parameters that remain in the modeling, the less complex the method is going to be. This scenario raises the chances of finding a uniform method and makes it easier to validate the model with field testing.

The output from the modeling of thermal conditions and behavior of a vegetated green roof is used as input to calculate the energy use of a residential building. Several field tests have been reported to make a validation of the transfer of output from thermal conditions and behavior to the input of energy use for heating and cooling.

Already in 2001, researchers tried to find out if vegetated green roofs could help reduce energy use. Researchers calculated with the energy-simulation program TRANSYS for a case study in Athens, in winter and in summer conditions (Niachou et al. 2001). Here it was shown that the results differ in the case of non-insulated roof constructions. As soon as the u-value goes below $0.75\left[\mathrm{~W} / \mathrm{m}^{2} \mathrm{~K}\right]$, an added value from the vegetated green roof can be omitted (Santamouris M. et al. 2007),

Liu et al. made an evaluation of thermal performance of vegetated green roofs in field experiments in Ottawa, Canada. The tests show that a layer of snow on the roof reduces the difference between a traditional black roof and a vegetated green roof completely. Without snow, the energy use of a room under a vegetated green roof was measured to be about $13 \%$ less. (Liu et al. 2003).

Table 2. Bandwidth of input parameters

\begin{tabular}{lllll}
\hline Symbol & Parameter & Daytime & Nighttime & 24 h Mean \\
\hline LAI & LAI (Leaf Area Index) & 2 & 2 & 2 \\
$\mathrm{f}$ & Density of vegetation & 0.9 & 0.9 & 0.9 \\
Waf & Wind velocity & $4 \mathrm{~m} / \mathrm{s}$ & $4 \mathrm{~m} / \mathrm{s}$ & $4 \mathrm{~m} / \mathrm{s}$
\end{tabular}




\begin{tabular}{|c|c|c|c|c|}
\hline Symbol & Parameter & Daytime & Nighttime & $24 \mathrm{~h}$ Mean \\
\hline$\alpha f$ & Short wave Albedo vegetation & 0.5 & 0.5 & 0.5 \\
\hline$\alpha g$ & Short wave Albedo substrate & 0.5 & 0.5 & 0.5 \\
\hline r'” & Humidity factor & 0.5 & 0.5 & 0.5 \\
\hline$\varepsilon f$ & Emissivity vegetation & 0.5 & 0.5 & 0.5 \\
\hline$\varepsilon g$ & Emissivity substrate & 0.5 & 0.5 & 0.5 \\
\hline Is & Short wave radiation & $270 \mathrm{~W} / \mathrm{m}^{2}$ & $0 \mathrm{~W} / \mathrm{m}^{2}$ & $191 \mathrm{~W} / \mathrm{m}^{2}$ \\
\hline Iir & Long wave radiation & $360 \mathrm{~W} / \mathrm{m}^{2}$ & $341 \mathrm{~W} / \mathrm{m}^{2}$ & $354 \mathrm{~W} / \mathrm{m}^{2}$ \\
\hline Tf & Temperature vegetation & $21^{\circ} \mathrm{C}$ & $12^{\circ} \mathrm{C}$ & $18^{\circ} \mathrm{C}$ \\
\hline $\operatorname{Tg}$ & Temperature substrate & $17^{\circ} \mathrm{C}$ & $13^{\circ} \mathrm{C}$ & $14{ }^{\circ} \mathrm{C}$ \\
\hline Taf & Temperature between vegetation & $20{ }^{\circ} \mathrm{C}$ & $14{ }^{\circ} \mathrm{C}$ & $17^{\circ} \mathrm{C}$ \\
\hline $\mathrm{T} 2$ & Temperature under substrate & $18^{\circ} \mathrm{C}$ & $13^{\circ} \mathrm{C}$ & $15^{\circ} \mathrm{C}$ \\
\hline
\end{tabular}

Table 2 shows the input variables used to estimate the bandwidth of the parameters defining conditions on vegetated green roofs used in the heat transfer model of Ouldboukhitine et al., based on the models from Sailor and Frankenstein (after Ouldboukhitine et al. 2011, based on the models of Sailor and Frankenstein 2004).

Van der Vel et al. did testing in a field experiment in Belgium. The climate there is similar to the Dutch moderate climate (Van der Vel et al. 2006). On two wintery days, vegetated green roofs were monitored for temperature on the top of the roof construction. The results showed that the effect of the vegetated green roof was considerable compared to the uncovered black roof and the roof with gravel. In fact, the uncovered roof and the gravel roof showed more amplitude than the outside air temperature, whereas the two vegetated green-roof constructions, light extensive and medium intensive, showed less amplitude. Next the mean u-value was reconstructed from the temperature readings.

The testers made a comparison between a traditional black roof and a vegetated green roof, while varying the uvalue of the roof construction. The results are shown in Table 3.

Table 3. Results of varying the u-value of roof constructions

\begin{tabular}{rrrr}
\hline $\begin{array}{c}\text { thickness of } \\
\text { insulation }[\mathrm{mm}]\end{array}$ & $\begin{array}{c}\text { u-value construction } \\
{\left[\mathrm{W} / \mathrm{m}^{2} \mathrm{~K}\right]}\end{array}$ & $\begin{array}{c}\text { energy use heating } \\
{\left[\mathrm{kWh} / \mathrm{m}^{2} / \text { year }\right]}\end{array}$ & $\begin{array}{c}\text { energy use heating } \\
{\left[\mathrm{kWh} / \mathrm{m}^{2} / \text { year }\right]}\end{array}$ \\
\hline & & traditional black roof & extensive green roof \\
& 0 & 133.6 & 69.8 \\
50 & 0.77 & 45.6 & 43.0 \\
100 & 0.40 & 36.0 & 36.1 \\
150 & 0.26 & 32.4 & 32.8 \\
200 & 0.20 & 30.5 & 31.0 \\
250 & 0.17 & 29.3 & 29.8 \\
300 & 0.13 & 28.5 & 29.0 \\
\hline
\end{tabular}

Table 3 shows the difference in energy use for heating for a one-family house with a traditional black roof and an extensive green roof according to Jaffal et al. 2012). For a $50 \mathrm{~mm}$ thickness of insulation, the difference seems 
negligible, taking inaccuracies into account.

Ray et al. developed a tool (MIT Design Advisor 2010) to estimate the differences from climate, building type, and roof type for energy use (Ray et al. 2010). The model was validated by two field experiments in Florida USA and in Japan. The calculated values match the measured values from the USA experiment. The data did not match very well from the Japan experiment. The difference of $26 \%$ was explained by the absence of roof insulation and other inaccuracies in the construction of the Japanese green roof. Based on this research, it seems reasonable to state that small differences in materials between the calculation model and the actual model are the probable source of inaccuracy.

Sailer et al. explored the effects of vegetated green roofs on the thermal performance of different types of buildings in the USA. There was variation in LAI and thickness of the soil-substrate layer (Sailor et al. 2011). The field test from roofs in the city of Portland (OR) are most interesting because its climate is similar to that in the Netherlands. The test is particularly interesting because it includes assessments for domestic buildings and for office buildings separately. Varying the LAI and the thickness of the soil-substrate layer shows a clear distinction in results as shown in Table 4.

Table 4. Variation of LAI for four types of roofs on two types of buildings: domestic and office. Variation in LAI and in the thickness of the soil substrate shows significant differences in energy use for heating

\begin{tabular}{|c|c|c|c|c|}
\hline Roof Type & LAI [-] & $\begin{array}{l}\text { Thickness Soil } \\
\text { Substrate }[\mathrm{mm}]\end{array}$ & $\begin{array}{c}\text { Energy Saving } \\
\text { domestic }[\%]\end{array}$ & $\begin{array}{c}\text { Energy Saving } \\
\text { office [\%] }\end{array}$ \\
\hline Roof One & 2 & 50 & 3.3 & 2.7 \\
\hline Roof Two & 2 & 150 & 5.0 & 2.9 \\
\hline Roof Three & 0.5 & 150 & 5.0 & 2.3 \\
\hline Roof Four & 5 & 150 & 4.3 & 3.4 \\
\hline
\end{tabular}

\section{Value of Modeling}

From the above-mentioned research papers, it can be concluded that modeling of thermal behavior throughout the years became more detailed and sophisticated. More variables in more differentiating parameters were tested, modeled, and validated under different conditions. Research papers show distinction between winter and summer conditions despite the dynamically changing conditions in the temperature and moisture of soil substrate and vegetation.

Modeling of thermal behavior of vegetated green roofs becomes complex due to three reasons. First, there are many variables influencing thermal behavior, and second, these variables are partly interlinked. Finally, variables change due to climate, season, weather, and the day- and night cycle.

For winter conditions, there is an acceptable conclusion. Only on non-insulated roofs is there a significant contribution of the vegetated-green-roof-soil substrate and vegetation to a reduction in energy use for heating. In all conditions where the roof construction is insulated moderately well, the energy use is not significantly influenced. Another important conclusion from the sequence of field tests and modeling attempts is that it is now known which models are considered to be validated. Some models currently used in scientific research are not validated directly by field tests, but by partial experiments and indirectly by field tests reported in papers.

The question is whether or not these models cover the area of parameters and variables found on extensive vegetated green roofs. To answer this question, four models were selected based on the criteria of covering the total vegetated-green-roof construction, scientifically published after 2010 and covering most city-climate conditions in the world, at least those in moderate climates. Four models were found and were then used in comparison:

Model Feng (Feng et al. 2010);

Model Ouidboukhitine (Ouidboukhitine et al. 2011);

Model Taberes-Velasco (Tabares-Velasco et al. 2012);

Model Djedjig (Djedjig et al. 2012). 
Table 5. All four models are listed and compared on the variable covered by the model considering the parameters describing short-wave and long-wave radiation. An empty reference box in the matrix means that there is no use of this specific variable in the model. An X in a reference box in the matrix means that there is a variable used in the model

\begin{tabular}{lcccc}
\hline \multicolumn{1}{c}{ Variable parameter } & $\begin{array}{c}\text { Model } \\
\text { Feng }\end{array}$ & $\begin{array}{c}\text { Model } \\
\text { Ouidboukhitine }\end{array}$ & $\begin{array}{c}\text { Model } \\
\text { Tabares-Velasco }\end{array}$ & $\begin{array}{c}\text { Model } \\
\text { Djedjig }\end{array}$ \\
\hline incoming radiation & $\mathrm{X}$ & $\mathrm{X}$ & $\mathrm{X}$ & $\mathrm{X}$ \\
coverage vegetation & & $\mathrm{X}$ & & $\mathrm{X}$ \\
LAI & $\mathrm{X}$ & $\mathrm{X}$ & $\mathrm{X}$ & $\mathrm{X}$ \\
Albedo vegetation & $\mathrm{X}$ & $\mathrm{X}$ & $\mathrm{X}$ & $\mathrm{X}$ \\
Albedo substrate & & $\mathrm{X}$ & $\mathrm{X}$ \\
transparency & $\mathrm{X}$ & $\mathrm{X}$ & $\mathrm{X}$ & $\mathrm{X}$ \\
vegetation & $\mathrm{X}$ & $\mathrm{X}$ & $\mathrm{X}$ \\
incoming radiation & $\mathrm{X}$ & $\mathrm{X}$ & $\mathrm{X}$ & $\mathrm{X}$ \\
coverage vegetation & $\mathrm{X}$ & $\mathrm{X}$ & $\mathrm{X}$ \\
LAI & $\mathrm{X}$ & $\mathrm{X}$ & $\mathrm{X}$ & $\mathrm{X}$ \\
emission vegetation & $\mathrm{X}$ & $\mathrm{X}$ & $\mathrm{X}$ & $\mathrm{X}$ \\
emission substrate & $\mathrm{X}$ & $\mathrm{X}$ & $\mathrm{X}$ & $\mathrm{X}$ \\
\hline temp. vegetation & & & \\
temp. substrate & & $\mathrm{X}$ & \\
temp. air & & $\mathrm{X}$ & & \\
\hline
\end{tabular}

From the comparison of models in Table 5, it becomes clear that the models do not differ in most variables. Only in Leaf Area Index (LAI) and transparency of the vegetation are there differences in the models of Fen, Ouidboukhitine, and Tabares-Velasco to the Djedjig model. This last model is also the model most recently published. The models of Ouidboukhitine, Tabares-Velasco, and Djedjig cover the same variables in heat exchange from evapo-transpiration, heat exchange through conductivity, and heat exchange through convection.

Table 6. The use of variables in four models for heat-exchange processes from convection, conductivity, and evapo-transpiration, or evaporation. Only the Feng model misses out on most of the variables. The other three models completely cover all variables representing parameters defining heat transfer in vegetated green-roof constructions

\begin{tabular}{lcccc}
\hline \multicolumn{1}{c}{ Variable parameter } & $\begin{array}{c}\text { Model } \\
\text { Feng }\end{array}$ & Model Ouidboukhitine & $\begin{array}{c}\text { Model } \\
\text { Tabares-Velasco }\end{array}$ & $\begin{array}{c}\text { Model } \\
\text { Djedjig }\end{array}$ \\
\hline air heat content & & $\mathrm{X}$ & $\mathrm{X}$ & $\mathrm{X}$ \\
coverage LAI & $\mathrm{X}$ & $\mathrm{X}$ & $\mathrm{X}$ \\
air movement & $\mathrm{X}$ & $\mathrm{X}$ & $\mathrm{X}$ \\
vegetation type & $\mathrm{X}$ & $\mathrm{X}$ & $\mathrm{X}$ \\
substrate type & $\mathrm{X}$ & $\mathrm{X}$ & $\mathrm{X}$ \\
sun intensity & $\mathrm{X}$ & $\mathrm{X}$ & $\mathrm{X}$
\end{tabular}




\begin{tabular}{llll} 
substrate moisture & $\mathrm{X}$ & $\mathrm{X}$ & $\mathrm{X}$ \\
air pressure & $\mathrm{X}$ & $\mathrm{X}$ & $\mathrm{X}$ \\
relative humidity & $\mathrm{X}$ & $\mathrm{X}$ & $\mathrm{X}$ \\
\hline latent heat transport & $\mathrm{X}$ & $\mathrm{X}$ & $\mathrm{X}$ \\
tempe. vegetation & $\mathrm{X}$ & $\mathrm{X}$ & $\mathrm{X}$ \\
heat transport conductivity & $\mathrm{X}$ & $\mathrm{X}$ & $\mathrm{X}$ \\
substrate moisture & $\mathrm{X}$ & $\mathrm{X}$ & $\mathrm{X}$ \\
thickness substrate & $\mathrm{X}$ & $\mathrm{X}$ & $\mathrm{X}$ \\
temp. difference & $\mathrm{X}$ & $\mathrm{X}$ & $\mathrm{X}$ \\
\hline
\end{tabular}

\begin{tabular}{llllll}
\hline air movement & X & X & X & X \\
\hline coverage LAI & & X & X & X \\
vegetation type & & X & X & X \\
substrate type & & X & X & X \\
Heat content air & X & X & X & X \\
temp. air & X & X & X & X \\
temp. vegetation & X & X & X & X \\
temp. substrate & & X & X & X \\
\hline
\end{tabular}

Parameters for heat storage in the mass of materials of vegetated green-roof construction are only taken into account by Feng and Djedjig. The heat generated internally under the vegetated green-roof construction is used as a variable in all models. All models can make a connection to energy-use calculations. Variables defining the parameter of photosynthesis are only used in the Feng model. The Ouidboukhitine model and the Djedjig model use two variables to model the parameter of water coming down on the vegetated green roof from rainfall and from the drainage capacity of the vegetated green-roof layers. The incoming radiation in short waves provides $99 \%$ of all incoming heat on a vegetated green roof (Feng et al. 2011). This variable is probably the most significant in the parameter defining short-wave-radiation exchange. In long-wave-radiation exchange, the emission of the several surfaces is probably most important for modeling. All four models cover these variables in this parameter. The heat exchange is completely modeled by Djedjig, Ouidboukhitine, and Tabares-Velasces. The Feng model only takes some variables from the parameter convection into account.

Two parameters have to be discussed separately: heat storage from mass in the vegetated green-roof construction and water balance. Both influence the dynamics of the heat transfer mechanisms. These parameters are taken into account by Feng and Djedjig. Seen from this parameter, the Djedjig model covers both. The overall question of this paper was how thermal parameters influence the thermal behavior of vegetated green roofs. From the perspective of building physics, the parameters of water balance and heat storage in mass influence cooling capacity more than insulating capacity. The energy derived from photosynthesis might not influence cooling capacity as much as the other two. According to Feng et al., photosynthesis accounts for $10 \%$ of all outgoing energy in summer conditions. In winter conditions, this process drops to almost $0 \%$ (Feng et al. 2011). Although the Djedjig model does not take photosynthesis into account, this model is the most complete in amount of variables representing parameters defining thermal behavior of vegetated green-roof construction. The question now is which of the variables is most sensitive for variations. Knowing that information provides the opportunity to rule out smaller variables for practical use and for validating by field testing. 
Table 7. The use of variables in four models covering the parameters of heat storage in mass of the vegetated green-roof construction, heat generated from internal sources and calculating energy use of the building under the vegetated green roof, energy from photosynthesis (only in the Feng model), and water-balance (only in the Ouidboukhitine and Djedjig models)

\begin{tabular}{|c|c|c|c|c|}
\hline Variable parameter & $\begin{array}{l}\text { Model } \\
\text { Feng }\end{array}$ & Model Ouidboukhitine & $\begin{array}{c}\text { Model } \\
\text { Tabares-Velasco }\end{array}$ & $\begin{array}{l}\text { Model } \\
\text { Djedjig }\end{array}$ \\
\hline heat storage capacity vegetation & $\mathrm{X}$ & & & $\mathrm{X}$ \\
\hline temp. vegetation & $\mathrm{X}$ & & & $X$ \\
\hline heat storage capacity substrate & $\mathrm{X}$ & & & $\mathrm{X}$ \\
\hline temp. substrate & $\mathrm{X}$ & & & $\mathrm{X}$ \\
\hline water content substrate & & & & $\mathrm{X}$ \\
\hline Energy use calculation & $\mathrm{X}$ & $\mathrm{X}$ & $\mathrm{X}$ & $\mathrm{X}$ \\
\hline sun intensity & $\mathrm{X}$ & & & \\
\hline $\mathrm{CO}_{2}$ content & $\mathrm{X}$ & & & \\
\hline water content vegetation & $X$ & & & \\
\hline air temperature & $\mathrm{X}$ & & & \\
\hline vegetation type & $X$ & & & \\
\hline incoming rain & & $X$ & & $\mathrm{X}$ \\
\hline capacity drainage & & $X$ & & $\mathrm{X}$ \\
\hline
\end{tabular}




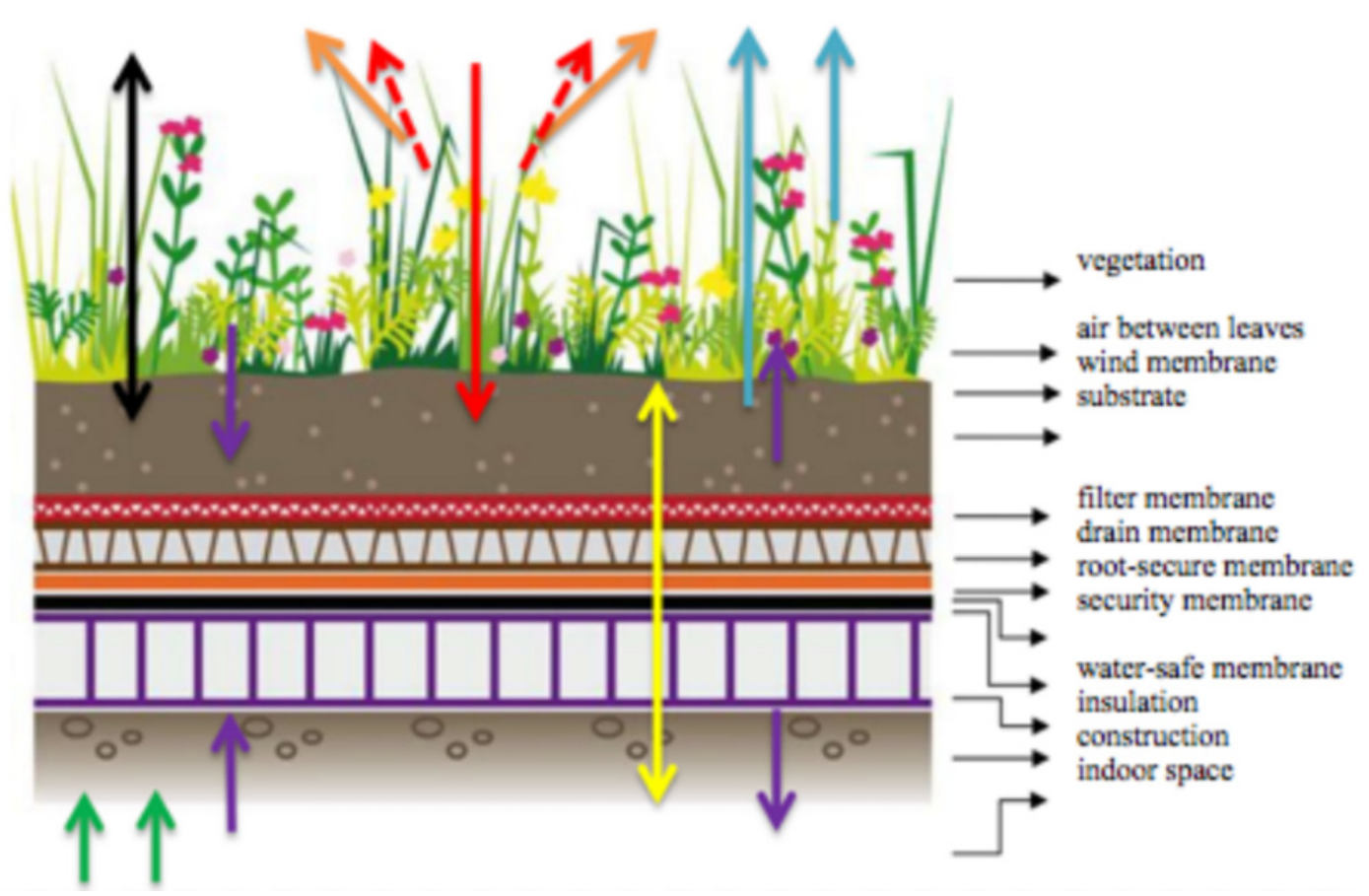

\begin{tabular}{|c|c|c|c|}
\hline 1 & $\begin{array}{l}\text { Short-wave heat-reflection absorption from } \\
\text { vegetation and substrate }\end{array}$ & $\pi$ & ' heat flux from conductivity through layers \\
\hline & $\begin{array}{l}\text { ' Long-wave heat-exchange between } \\
\text { ' layers, vegetation and substrate, to } \\
\text { ' atmosphere }\end{array}$ & & ' heat storage in mass of materials \\
\hline & $\begin{array}{l}\text { ' Long-wave heat-exchange between } \\
\text { layers, vegetation and substrate, to atmosphere }\end{array}$ & & heat from persons and installations \\
\hline & $\begin{array}{l}\text { ' heat loss trough evaporation of water in the } \\
\text { substrate and through vegetation }\end{array}$ & & $\begin{array}{l}\text { 'heat from photosynthesis in the vegetation } \\
\text { is not taken into account }\end{array}$ \\
\hline
\end{tabular}

Figure 1. above shows the layers in a typical extensive green-roof construction with the physical parameters that usually show up in thermal models (Feng et al. 2010, Ouidboukhitine et al. 2011, Tabares-Velasco et al. 2012,

Djedjig et al. 2012)

\section{Sensitivity Analysis}

For winter conditions, a sensitivity analysis can show which variables within which parameter categories most significantly influence energy-use calculation.

For winter conditions, the model of Djedjig was adopted and put into an excel spreadsheet calculation. Here, all variables were varied between minimum and maximum values. These values were found in the literature and from reports of field testing. The mathematical formula for energy balance of the vegetation layer according to the Djedjig model is:

$(\rho c p) f=$ Volume thermic capacity vegetation $(\mathrm{J} / \mathrm{m} 3 \mathrm{~K})$

$$
\left(\rho c_{p}\right)_{f} d_{f} F \frac{d T_{f}}{d t}=R_{n, f}+H_{f}+L_{f}
$$

$\mathrm{df}=$ Mean leaf thickness $(\mathrm{m})$

$\mathrm{F}=$ Leaf Area Index (-) 
$\mathrm{Tf}=$ Temperature vegetation (Kelvin)

$\mathrm{dt}=$ Time interval $(\mathrm{s})$

$\mathrm{Rn}, \mathrm{f}=\quad$ Net radiation absorbed by vegetation $(\mathrm{W} / \mathrm{m} 2)$

$\mathrm{Hf}=\quad$ Visible heat-flux vegetation $(\mathrm{W} / \mathrm{m} 2)$

$\mathrm{Lf}=$ Latent heat-flux vegetation $(\mathrm{W} / \mathrm{m} 2)$

The mathematical formula for the energy balance of the substrate layer according to the Djedjig model is:

$$
\left(\rho c_{p}\right)_{g, \omega_{g}} \frac{\partial T}{\partial t}=\frac{\partial}{\partial z}\left(k_{\omega_{g}} \frac{\partial T}{\partial z}\right)
$$

$(\rho c p) g, \omega g=$ Volume thermic capacity substrate including water content $(\mathrm{J} / \mathrm{m} 3 \mathrm{~K})$

$\mathrm{T}=$ Temperature interval substrate surface and substrate layer (Kelvin)

$\mathrm{t}=$ Time interval $(\mathrm{s})$

$\mathrm{z}=$ Thickness substrate layer $(\mathrm{m})$

$\mathrm{k} \omega \mathrm{g}=\quad$ Thermic conductivity substrate with water content $(\mathrm{W} / \mathrm{Ks})$

A third mathematical formula from the Dejdjig model is used to calculate the evapo-transpiration, the energy exchange due to evaporation of water in the substrate layer:

$\mathrm{Lf}=$ Latent heat flux vegetation $(\mathrm{W} / \mathrm{m} 2)$

$$
E=-\left(L_{f}+L_{g}\right) / l_{v}
$$

$\mathrm{Lg}=$ Latent heat flux substrate $(\mathrm{W} / \mathrm{m} 2)$

$\mathrm{lv}=$ Latent heat evaporation $(\mathrm{J} / \mathrm{kg})$

The above-mentioned three formulas were combined and simplified to be able to use them in an excel spread sheet

Only a few of the variables in the parameters can be influenced by design. The bandwidth of influence was found in the literature and from reasoning. This list of variables also cannot be influenced by design. These variables were fixed in the calculation since the sensitivity of these variables is not of concern in this research.

Table 8 . The results of the sensitivity analysis for winter conditions in eleven variables. The most significant variables by far are the mass-heat-transport resistance of the vegetation surface and the Leaf Area Index (LAI)

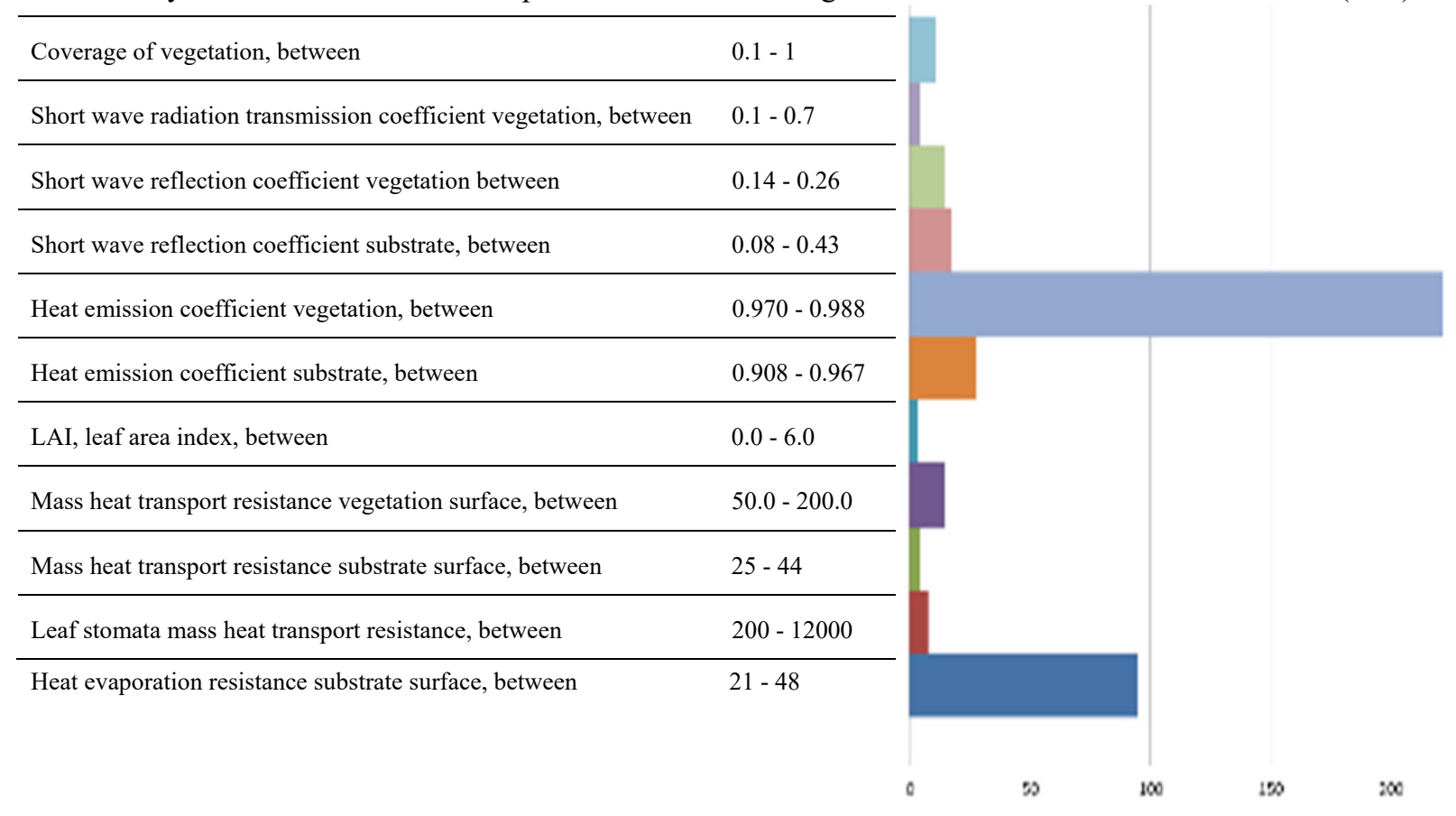


Heat evaporation resistance substrate surface

Mass heat transport resistance substrate surface

Heat emission coefficient substrate

Leaf stomata mass heat transport resistance

Mass heat transport resistance vegetation surface

Transparency vegetation

Heat emission coefficient substrate

Short wave reflection coefficient substrate

Short wave reflection coefficient vegetation

Coverage of vegetation

\section{Leaf Area Index LAI}

As is shown in Table 8, the most significant variables, mass-heat-transport resistance of the vegetation surface and the Leaf Area Index (LAI), are followed by transparency of the vegetation and leaf-stomata mass-heattransport resistance. All four are variables directly connected to the vegetation. Since vegetation is growing and flowering, reacting to changing circumstances, there is little influence on these variables from the point of view of a designer. A gardener might be able to keep the vegetation within certain limitations of the variables by intensive maintenance. On the other hand, the vegetation in most winter conditions changes less.

Taking a closer look at the energy balances, substrate and vegetation, variations in coverage of the vegetation influence both significantly. The more plants grow and cover the substrate, the more the energy balance of the vegetation is influenced. On the other hand, the more that plants cover the substrate, the less this coverage influences the energy balance of the substrate. From this analysis, both counter compensate, so the influence is not visible in the overall modeling.

For the average for day- and night-time conditions, the most significant factors are humidity of the substrate, the Albedo of the vegetation, and third, the LAI. The variations in humidity of the substrate can have a widespread effect. This effect is caused by the dynamics in the conditions as well as by the system specifications. LAI and Albedo depend on choice of specific species of vegetation. The results of the sensitivity analysis match results from field tests as given in research papers.

\section{Energy-use calculations for residential buildings}

Looking at the conclusions of the energy balances for winter conditions, it is interesting to know if changes in the thermal specifications of vegetated green roofs, compared to traditional black roofs, would show up in energy-use calculations for residential buildings.

For winter conditions in a moderate climate, these calculations were made for an average Dutch single-family row house. There is a clear conclusion. Every Dutch single-family row house with insulation better than 1.50 $\mathrm{m}^{2} \mathrm{k} / \mathrm{W}$ does not show any improvement in energy use. Since 1992, the minimum demand for insulation for housing in The Netherlands is $2.5 \mathrm{~m}^{2} \mathrm{k} / \mathrm{W}$. This figure was raised to $3.5 \mathrm{~m}^{2} \mathrm{k} / \mathrm{W}$ on March 1. 2013. It has been the average for newly built houses for years. In 2015, this demand will be raised to $5 \mathrm{~m}^{2} \mathrm{k} / \mathrm{W}$. At this level of insulation, there will be little influence from the improved u-value of an extensive green roof. Four different levels of insulation, following the legal increase in the R-value in the Netherlands from 1970 to the present, energy-use calculations were made for an average single-family row house. Besides insulation values, the uvalues for glazing were also improved. The variables for the extensive green roof were set to standard. The influence, and sensitivity, from vegetated green roofs on the total energy use is decreasing. This result matches research by Kotsiris (Kotsiris et al. 2012).

Table 9. The raise in R-Value in Dutch Regulations for insulation of buildings

\begin{tabular}{lcccc}
\hline Building & 1970 & 1988 & 2012 & 2015 \\
\hline Roof, facade and floor & $0.22 \mathrm{~m}^{2} \mathrm{~K} / \mathrm{W}$ & $1.5 \mathrm{~m}^{2} \mathrm{~K} / \mathrm{W}$ & $3.5 \mathrm{~m}^{2} \mathrm{~K} / \mathrm{W}$ & $5 \mathrm{~m}^{2} \mathrm{~K} / \mathrm{W}$ \\
Glazing & single & double & double HE & triple \\
Decrease energy use $\%$ & $21.7 \%$ & $7.1 \%$ & $3.6 \%$ & $2.7 \%$ \\
\hline
\end{tabular}


Vegetated Green roofs that are specifically designed to improve the u-value, can be excluded from this conclusion. Ne research in this area has been entered by researchers that influence green roofs actively under fixed conditions and measuring changes in the u-value (Rochea Berardib 2014, Ouldboukhitinea et al. 2014)). Another exception can be a vegetated green-roof system with a layer of dry air between the roof and the substrate layer. These kinds of vegetated green roofs are under development to improve the water buffering and slowing down of runoff water.

\section{Discussion, Verification, and Validation}

Analysis of the results from modeling and validating thermal models for vegetated green roofs shows that models are either used to theorize field-test results or models are validated with field tests. During the last ten years, models became more sophisticated. From the analysis, it was possible to choose the Djedjig model for calculations under winter conditions in this research. In other literature, parameters were found that ware used to describe the thermal behavior of the vegetated green roof. Parameters are mostly dedicated to one layer of the vegetated green roof: the vegetation layer, the substrate layer, or the construction layer. Each parameter was transformed into a mathematical formula including physical variables representing either outside conditions, technical specifications of the vegetated green roof, or thermal processes in or between layers.

With this information, the sensitivity analysis for winter conditions was made. The analysis was used to make conversion possible from worldwide field-test data to models for the Dutch moderate climate. From the sensitivity analysis it became clear that differentiating between winter and summer was indeed necessary. Most sensitive and significant variables can be calculated with estimations of the values in moderate winter conditions.

For the Dutch winter climate and weather conditions it is concluded that extensive green roofs will not add to extra u-value or R-value of roof construction. Most significant variables are typically attached to the vegetation layer: mass heat-transport resistance of the vegetation surface, Leaf Area Index LAI, transparency of the vegetation and leaf-stomata mass-heat-transport resistance of the vegetation. These variables are not used in energy use calculations. In winter, these conditions hardly change, so the model would not be sensitive to these variables. Even if there were some minor contribution, it would not show in an energy calculation for heating.

Under Dutch climate and weather conditions, there is little contribution from extensive green roofs to the u-value of roof construction. Most contribution can be expected from humidity of the substrate, Albedo short-wave radiation of the vegetation and the LAI. From the results of modeling for Dutch conditions, within parameters of general models and within variations of variables in a sensitivity analysis, results do not match field tests from the literature (Van der Vel et al.2006). The results do match the results from Belgian field testing in a climate most closely related to the Dutch conditions. For moderate climate conditions in a location in the south of Brazil, energy savings were measured in field testing for heating and cooling (Parizotto et al. 2011; D'Orazioa et al. 2012). This result also matches the conditions and conclusions for the Dutch sensitivity analysis.

\section{Conclusion on Thermal Specifications}

The conclusion of this research is that winter conditions in the Dutch moderate climate can be modeled and understood in terms of physical parameters and variables. A sensitivity analysis for winter conditions shows vegetated green-roof thermal parameters and shows the significance of only a small number of variables influencing thermal behavior. For the winter situation this factor will negligible. U-value and R-value adjustments cannot be made within reasonable boundaries of accuracy. Moreover, any contribution will not show up in energy-use calculations for heating.

The conclusions hold some potential for innovation. Extensive green roofs for moderate climates can hardly be improved or further optimized for reducing energy for heating residential buildings. Therefore, no uniform method or model is needed during the commissioning of green-vegetated roofs. Dutch public-policy makers do not have to make supportive governance models for thermal specifications of green-vegetated roofs (Teeuw, P.G. Ravesloot C.M. 2009). An exception may occur for those on buildings with considerable cooling loads, as in residential buildings for elderly people and mixed-use buildings.

\section{Acknowledgments}

The research was funded by SIA Stichting Innovatie Alliantie at the Netherlands Organization for Scientific Research Thank you also to over thirty SME companies in the Netherlands and Germany, represented by the Dutch Association for Green Building Engineers (VBB) and the Dutch association for Green Roofs and Green Facades (VHG). Special thanks go out to the European Green Roof Association and the American Green Roofs for Healthy Cities Community. I would like to thank Wim Verburg M.Sc. and Dr. Carleen Mesters for their management support and Lee Martin M.Sc. for his help in correcting and final editing of the manuscript. Special 
thanks go to the students that assisted in the research: Pepijn Somers, Marc Delemarre, Erik Huang and Mitchel Klaasman.

\section{References}

Alexandri, E., \& Jones, P. (2008). Temperature decreases in an urban canyon due to green walls and green roofs in diverse climates. Building and Environment, 43(4), 480-493.

Banting, D. et al. (2005). Report on the Environmental Benefits and Costs of Green Roof Technology for the City of Toronto, Dept. of Architectural Science, Ryerson University.

Castleton, H. F., Stovin, H. F., Beck, S. B. M., \& Davison, J. B. (2010). Green roofs; building energy savings and the potential for retrofit. Energy and Buildings, 42(10), 1582-1591.

D’Orazio, M., Perna, C. Di, \& Giuseppe, E. Di. (2012). Green roof yearly performance: A case study in a highly insulated building under emperate climate. Energy and Buildings, 55, 439-451.

Deardoff, J. W. (1987). Efficient prediction of ground surface temperature and moisture, with inclusion of a layer of vegetation. Journal of Geophysical Research, 83(4), 1889-1903.

Del Barrio, E. P. (1998). Analysis of the green roofs cooling potential in buildings. Energy Build, 27(2), 179193.

Delemarre, M., \& Somers, P. (2012). Insulating effect of vegetated green roofs in summer (de isolerende werking van begroeide daken in de zomer), Bachelor Thesis, Rotterdam University of Applied Science, Sustainable Solutions;

Djedjig, R., Ouldboukhitine, S. E., Belarbi, R., \& Bozonnet, E. (2012). Development and validation of a coupled heat and mass transfer model for green roofs. International Communications in Heat and Mass Transfer, 39(6), 752-761.

Feng, C., Meng, Q., \& Zhang, Y. (2010). Theoretical and experimental analysis of the energy balance of extensive green roofs. Energy Build, 42(6), 959-965.

Frankenstein, S., \& Koenig, G. (2004). FASST vegetation models. Technical Report TR-04-25. Hanover, NH: US Army Engineer Research and Development Center, Cold Regions Research and Engineering Laboratory.

Getter, K. L., Rowe, D. B., Andresen, J. A., \& Wichman, I. S. (2011). Seasonal heat flux properties of an extensive green roof in a Midwestern U.S. Climate. Energy and Buildings, 43(12), 3548-3557.

Hilten R. (2005). An analysis of the energetic and stormwater mediation potential of green roofs, M.S. Thesis, Department of Biological and Agricultural Engineering, University of Georgia, Athens.

Huang, E. C. X. (2013). Thermal effects of vegetated green roofs in winter (De thermische werking van begroeide daken in de winter), Bachelor Thesis, Rotterdam University of Applied Science, Sustainable Solutions;

Jaffal, I., Ouldboukhitine, S. E., \& Belarbi, R. (2012). A comprehensive study of the impact of green roofs on building energy performance. Renewable Energy, 43, 157-164.

Jim, C. Y., \& Peng, L. H. (2011). Weather effect on thermal and energy performance of an extensive tropical green roof. Urban Forestry \& Urban Greening, 11(1), 73-85.

Jim, C. Y., \& Tsang, S. W. (2010). Biophysical properties and thermal performance of an intensive green roof. Building and Environment, 46(6), 1263-1274.

Klaasman M. (2013). Added value with cooling from increased Delta $T$ by green roofs (de meerwaarde van koeling door een grotere Delta T bij begroeide daken), Bachelor Thesis, Rotterdam University of Applied Science, Sustainable Solutions;

Kotsiris, G., Androutsopoulos, A., Polychroni, E., \& Nektarios, P. A. (2012). Dynamic U-value estimation and energy simulation for green roofs. Energy and Buildings, 45, 240-249.

Kumar, R., \& Kaushik, S. C. (2005). Performance evaluation of green roof and shading for thermal protection of buildings. Building and Environment, 40(11), 1505-1511.

Liu, K., \& Baskaran, B. (2003). Thermal performance of green roofs through field evaluation, National Research Council, Institute for Research in Construction, Ottawa.

Lundholm, J. T., Weddle, B. M., \& MacIvor, J. S. (2014). Snow depth and vegetation type affect green roof 
thermal performance in winter. Energy and Buildings, 84, 299-307.

Morau D., Libelle T., \& Garde F. (2012). Performance Evaluation of Green Roof for Thermal Protection of Buildings In Reunion Island, Energy Procedia 14 pages 1008- 1016.

Niachou, A., \& Papakonstantinou, K. (2001). Analysis of the green roof thermal properties and investigation of its energy performance. Urban Forestry \& Urban Greening, 33(7), 719-729.

Ouldboukhitine, S. E., Belarbi, R., Jaffal, I., \& Trabelsi, A. (2011). Assessment of green roof thermal behavior: A coupled heat and mass transfer model. Building and Environment, 46(12), 2624-2631.

Ouldboukhitinea, S. E., Spolekb, G., \& Belarbia, R. (2014). Impact of plants transpiration, grey and clean water irrigation on the thermal resistance of green roofs. Ecological Engineering, 67, 60-66.

Parizotto S., \& Lamberts R. (2011). Investigation of green roof thermal performance in temperate climate; A case study of an experimental building in Florianopolis city, Southern Brazil. Energy and Buildings, 43(7), $1712-1722$.

Ray, S., \& Glicksman, L. (2010). Potential Energy Savings of Various Roof Technologies, Building Technology and Mechanical Engineering at Massachusetts Institute of Technology, Cambridge, ASHRAE Transactions;

Rochea, P. La, \& Berardib, U. (2014). Comfort and energy savings with active green roofs. Energy and Buildings 82, 492-504.

Sailor, D., Elley, T. B., \& Gibson, M. (2011). Exploring the building energy impacts of green roof design decisions - a modeling study of buildings in four distinct climates. Journal of Building Physics, 35(4), 372 391.

Sailor, D. J. (2008). A green roof model for building energy simulation programs, Energy Build 40 (8) pages 1466-1478.

Sailor, D. J., Hutchinson, D., \& Bokovoy, L. (2008). Thermal property measurements for ecoroof soils common in the western U.S. Energy Build, 40 (7), 1246-1251.

Santamouris, M., Pavlou, C., Doukas, P., Mihalakakou, G., Synnefa, A., Hatzibiros, A., \& Patargias, P. (2007). Investigating and analyzing the energy and environmental performance of an experimental green roof system installed in a nursery school building in Athens. Energy, 32(9), 1781-1788.

Sfakianaki, A., Pagalou, E., Konstantinos, Pavlou, K., Santamouris, M., \& Assimakopoulos, M. N. (2009). Theoretical and experimental analysis of the thermal behaviour of a green roof system installed in two residential buildings in Athens, Greece. International Journal of Energy Research, 33(12), 1059-1069.

Susca, T., Gaffin, S. R., \& Dell'Osso, G. R. (2011). Positive effects of vegetation: Urban heat island and green roofs. Environmental Pollution, 159(8-9), 2119-2126.

Tabares-Velasco, et al. (2012). A heat transfer model for assessment of plant based roofing systems in summer conditions. Building and Environment, 49, 310-323.

Teeuw, P. G., \& Ravesloot, C. M. (2009). Organization of large scale green covered roofs improving the collaboration of policy makers with urban designers. In L Qu, C Yang, X Hui, \& D Sepulveda (Eds.), The New Urban Question: Urbanism Beyond Neoliberalism, pages 445-450. Delft: International Forum on Urbanism.

Townshend, D. (2007). Study on green roof application in Hong Kong, Architectural service department, Hong Kong;

Van der Vel L., \& Raymaekers, D. (2006). WTCB Technische voorlichting 229 Groendaken, Technical information 229 Green Roofs, Brussels;

Wong, N. H., Cheong, D. K. W., Han, Y., Soh, J., Ong, C. L., \& Sia, A. (2003). The effects of rooftop garden on energy consumption of a commercial building in Singapore. Energy Build, 35(4), 352-364.

\section{Copyrights}

Copyright for this article is retained by the author(s), with first publication rights granted to the journal.

This is an open-access article distributed under the terms and conditions of the Creative Commons Attribution license (http://creativecommons.org/licenses/by/3.0/). 